\title{
A NEW SPECIES OF CAENoHomalopoda TACHIKAWA (HYMENOPTERA: ENCYRTIDAE) FROM MIZORAM, INDIA
}

\author{
Sudhir Singh \\ Systemaitic Laboratory, Forest Entomology Division, Forest Research Institute, P.O. New Forest, Dehradun, Uttranchal 248006, India \\ Email: sudhirs@icfre.org
}

\begin{abstract}
A new species of encyrtid genus Caenohomalopoda Tachikawa based on a female has been described. Key to the world species of Caenohomalopoda Tachikawa, based on females is also provided.

\section{KEYWORDS}

Caenohomalopoda, Encyrtidae, Hymenoptera, Mizoram, new species
\end{abstract}

\section{Genus: Caenohomalopoda Tachikawa}

Caenohomalopoda Tachikawa, 1979: 169.

Type species: Pseudhomalopoda shikokuensis Tachikawa, by original designation

The genus Caenohomalopoda contains five species distributed in eastern Palaearctic (C. shikokuensis \& C. koreana), Oriental ( $C$. longiclava \& C. nagaii) and Australasian (C. guamensis) regions. Some important literatures on this genus are as follows: Tachikawa (1956, 1978, 1979), Tachikawa et al. (1981), Noyes and Hayat (1984), Hayat et al. (2002), Basha and Hayat (2002).

The present Indian species is not con-specific with the other known species and has exceptionally big body size and very long exerted ovipositor. Therefore, generic characters are broadened to receive this Indian representative, which are as follows: Female, general body colour black with metallic green reflections; fore wings infuscated with rays and bands. Occipital margin not sharp; below fronto-vertex and above scrobes a narrow horizontally placed groove is present; head about $1.3 \mathrm{x}$ as wide as long, about $2.5 \mathrm{x}$ as wide as fronto-vertex; antenna nine-segmented: funicle four- and club three-segmented, later rounded at apex; mandible quadridentate, dorsal two teeth acute, ventral ones longer and subequal. Thorax flat; mesopleuron not touching the gaster; pronotum large, triangular in outline dorsally, posterior margin concave in the present species (not straight as mentioned by Noyes \& Hayat, 1984); medially about half as long as mesoscutum; axillae meeting narrowly; scutellum slightly convex, and its apex coming to the level of propodeum gradually, apex with a pair of long scale like setae; propodeum very short; marginal vein $4 \mathrm{x}$ as long as wide, postmarginal vein short about 0.25 of marginal, shorter than stigmal; hind wings hyaline. Gaster (excluding ovipositor) twice as long as thorax, pointed at tip, hypopygium reaching half the gaster length; ovipositor exserted greatly.

The genus belongs to tribe Habrolepidini and subtribe Habrolepidina. The members of this genus are parasitoids of Odonaspis species (Homoptera: Diaspididae) attacking bamboos. In this paper a new species is described. All the measurements given in the description are in millimeters except as otherwise stated.

\section{Caenohomalopoda longistylata sp. nov.}

(Figs. 1-10).

\section{Material examined}

Holotype: Female, on card bearing no. E50, 16.ix.1995, Mizoram, Kolasib Forest with Pinus insularis, shrubs and tall grasses; coll. Sudhir Singh, National Forest Insect Reference Collection, Forest Entomology Division, Forest Research Institute, Dehradun, India, Accession No. 21084.

Paratype: Female, left antenna, wings and legs, right mandible, mouth parts and gaster dissected and mounted on a slide, rest on a card; data same as for holotype.

\section{Etymology}

Latin: longus $=$ long, stylata $=$ ovipositor. Refers to long exserted ovipositor.

\section{Diagnostic features}

Female: Total body length excluding exserted part of ovipositor, $2.58 \mathrm{~mm}$, exserted part of ovipositor, $0.634 \mathrm{~mm}$ (holotype). Paratype female $2.39 \mathrm{~mm}$ without exserted part of ovipositor which is $0.73 \mathrm{~mm}$ long. Head black with metallic reflections; frontovertex metallic green with deep reticulate punctation, smaller than that on thorax; setae short and pale; below frontovertex and above there is a horizontal shallow groove; scrobal area with golden reflections; antennal prominence greenish with golden hue; malar space with greenish reflections, area below lower margin of eye with peacock violet blue; face below carina with fine longitudinal reticulations, setae silvery white, setal points clearly visible; eyes chocolate brown, asetose; ocelli light red; antenna black, apex of F3 slightly yellowish, F4 completely dull yellow. Thorax black dorsally and dark brown ventrally; prothorax and scutum complete and sides of scutellum with strong green reflections as on frontovertex; axillae with dull reddish-brown reflections; scutellum centrally with reddish-golden reflections; pronotum and mesoscutum with shallow honey comb like sculpture; anterior portion of pronotum with more prominent and deeper sculpture; sides of scutellum, corresponding to the greenish reflection, smooth and glabrous, central portion with deeper and more prominent sculpture as compared with mesoscutum; legs dark brown except following yellowish areas both ends of fore femur, tibiae and tarsal segments of all the legs, pretarsi with brownish tinge. Fore wings infuscated as in figure 10; hind wings hyaline. Gasteral first tergite with bluish-green reflections.

Head: In frontal view (Fig. 1) 1.31x as wide as long (430:328), 2.59x as wide as frontovertex (430 : 166); eye 1.72x as long as wide (200: 116), diverging ventrally from level of median ocellus; toruli oval, their width below the line joining the lower margins of the eye, 1.2 $\mathrm{x}$ as long as wide (54 : 45); torulo eye distance (84) $1.55 \mathrm{x}$, torulo mouth distance (104) $1.92 \mathrm{x}$ (not possible to realize this ratio in this posture due to high convexity of the region), inter torular distance (52) shorter than torular length (54), respectively. In dorsal view (Fig. 2) $1.75 x$ as wide as long (430:245), 
1

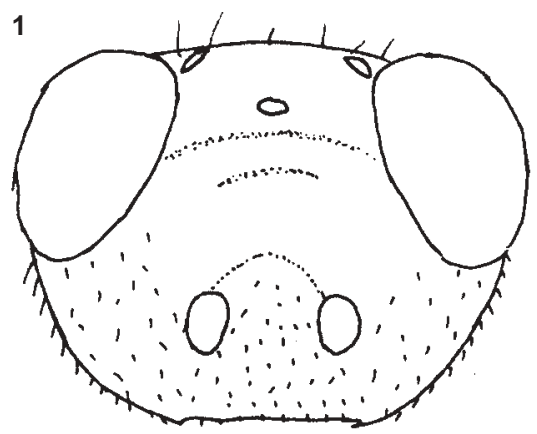

2

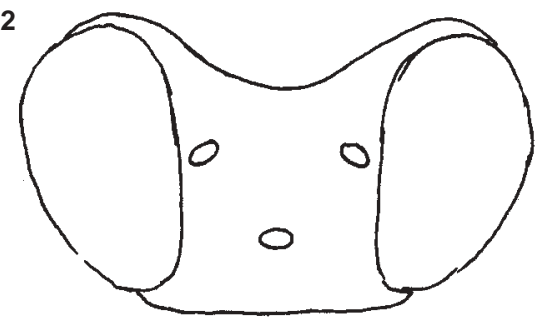

3

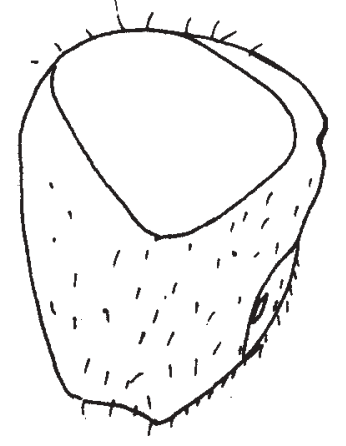

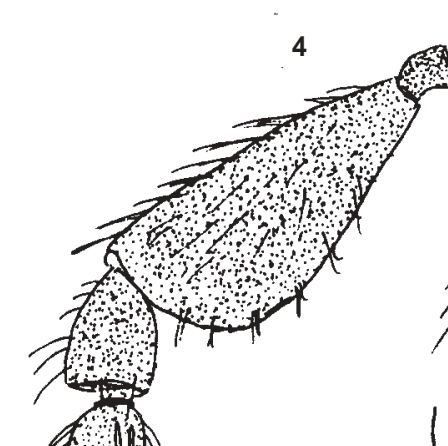
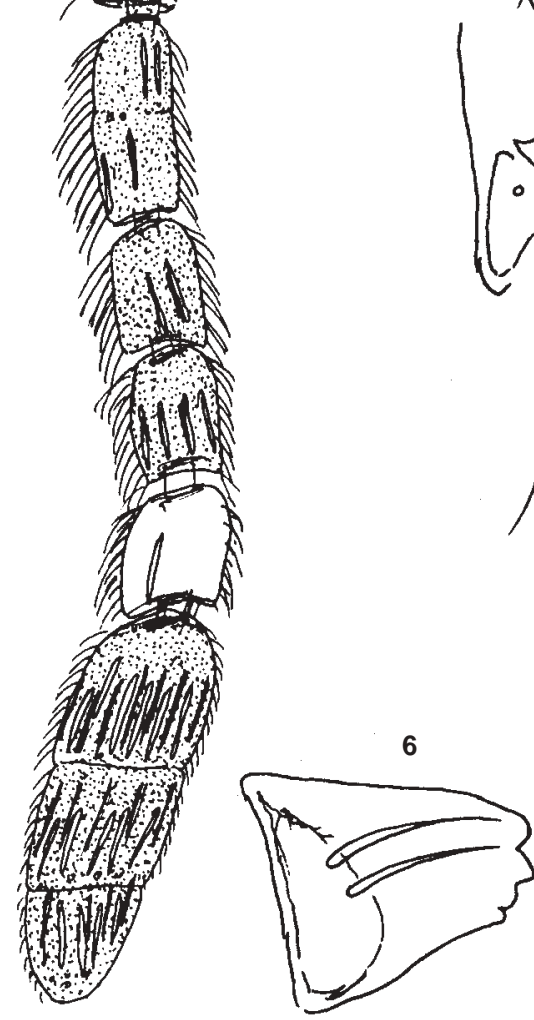

5
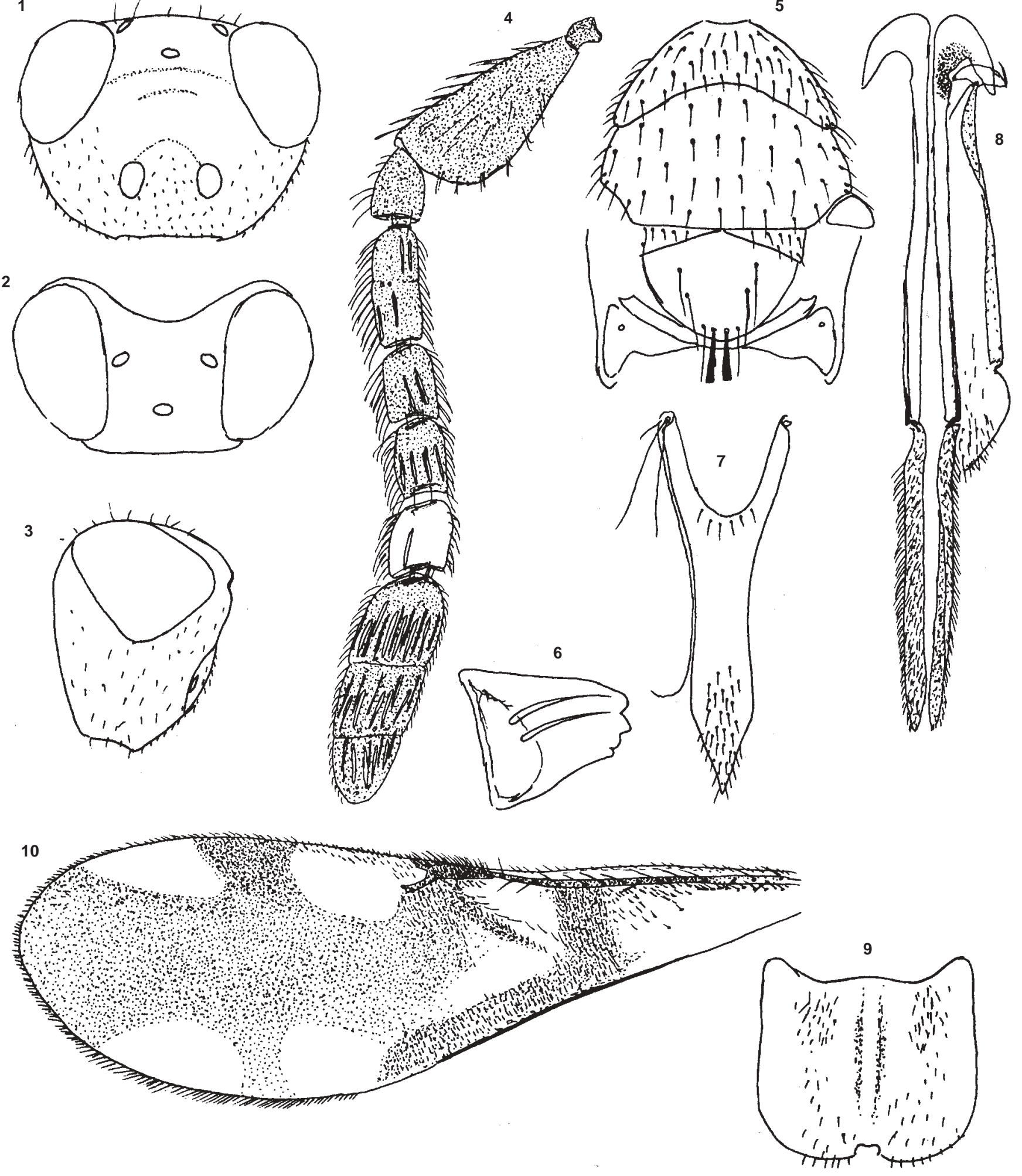

Figures 1-10. Caenohomalopoda longistylata sp. nov. (female).

1 - Head in frontal view; 2 - Head in dorsal view; 3 - Head in profile; 4 - Antenna; 5 - Thorax in dorsal view; 6 - Mandible; 7 - Last gasteral tergite; 8 - Ovipositor; 9 - Subgenital plate; 10 - Fore wing. 
posterior margin deeply rounded and concave, anterior slightly convex; eye $1.84 \mathrm{x}$ as long as wide $(223: 121)$, inner margins parallel to each other; frontovertex slightly longer than wide (178: 166); ocelli arranged in right angle triangle; posterior ocellar line (102) 4x, collar ocellar line (52) $2 x$ and ocello-ccular line (10) $0.4 x$ as long as diameter of median ocellus (25). In profile (Fig. 3) 1.26x as long as high (328:259); slightly triangular, frontovertex at right angle to facial area; eye 1.16x a long as wide (214 : 183); malar space $0.48 \mathrm{x}$ as long as head length $(160: 328)$. Antenna (Fig. 4, paratype) with scape 1.96x as long as wide (171:87); pedicel 1.24x as long as wide (67:54); F1 (113:42) 2.6x; F2 (67:47) 1.42x; F3 (74 : 50) 1.48x; F4 (76:62) 1.22x; and club (225:71) 3.16x as long as wide. Mandible as in Fig. 6 (paratype). Maxillary and labial palpi fourand three-segmented, respectively.

Thorax: (Fig. 5) In dorsal view, pronotum arch shaped, triangular, 2x as wide as long (447 : 222) medially $3.12 \mathrm{x}$ as wide as long (447: 143); mesoscutum flat, $1.75 \mathrm{x}$ as wide as long (504: 287); axillae meeting narrowly; scutellum 1.42x as wide as long (304 : 213); propodeum very narrow medially, scutellum apex sloping smoothly to the level of propodeum. Fore wing (Fig. 10, paratype) $3.12 \mathrm{x}$ as long as wide (1675 :536); marginal vein 4.48x as long as wide (121:27); stigmal vein $1.3 \mathrm{x}$ as long as postmarginal vein (42:32); hind wing (paratype) $4.5 \mathrm{x}$ as long as wide (1192 : 264), 1.56x as long as vein length (764). Middle leg tibial spur (paratype) shorter than basitarsus $(240: 267)$.

Gaster: Long, tapering posteriorly, 3.33x as long as wide (1463 : 439), $1.5 \mathrm{x}$ as long as combined lengths of head and thorax (1463 : 927); cercal plates at 0.25 of gaster length from base; hypopygium reaching $0.5 \mathrm{x}$ along gaster, exserted part of ovipositor $0.5 \mathrm{x}$ gaster length; $\mathrm{X}$-tergum (Fig. 7, paratype) about $3 \mathrm{x}$ as long as wide (1139: 382), anterior margin deeply concave, apex narrow and pointed; hypopygium (Fig. 9, paratype) quadrate, wider than long (643: 579); ovipositor (Fig. 8, paratype) $1.35 \mathrm{x}$ as long as gaster (2150: 1585), $2.4 \mathrm{x}$ as long as III-valvula (1257 : 893), 1.17x as long as its length beyond articulation with Ivalvifer (1071), outer plate 6.68x as long as wide (1196: 179).

\section{Male}

Unknown.

Host

Unknown.

\section{Remarks}

This new species can readily be distinguished from other known species on the basis of its large body, longer first funicle segment and the exserted ovipositor, as given in the key to the species.

\section{REFERENCES}

Basha, M.C. and M. Hayat (2002). Description of two new species of Encyrtidae (Hymenoptera: Chalcidoidea) from India. Zoos' Print Journal 17(6): 791-794.

Hayat, M., S. Manickavasagam and S. Suresh (2002). Records of some Encyrtidae (Hymenoptera: Chalcidoidea) from Tamil Nadu, India. Zoos' Print Journal 17(4): 769.

Noyes, J.S. and M. Hayat (1984). A review of the genera of Indo-Pacific Encyrtidae (Encyrtidae: Chalcidoidea). Bulletin of British Museum (Natural History) (Entomology) 48: 131-395.

Tachikawa, T. (1956). Description of a new species of the genus Pseudhomalopoda Girault from Japan, with a list of the known species and their hosts of the Habrolepis like genera (Hymenoptera: Encyrtidae). Insecta Matsumurana 20(3-4): 90-96

Tachikawa, T. (1978). A new species of Pseudhomalopoda from Indonesia (Hymenoptera: Chalcidoidea-Encyrtidae). Transactions of Shikoku Entomological Society 14(1-2): 65-67.

Tachikawa, T. (1979). A revision of the genus Pseudhomalopoda Girault with the description of a new genus (Hymenoptera: Chalcidoidea-Encyrtidae). Transactions of Shikoku Entomological Society 14(3-4): 163-170.

Tachikawa, T., W.H. Paik and J.C. Paik (1981). A new species of the genus Caenohomalopoda Tachikawa (Hymenoptera: Encyrtidae) parasitic on Odonaspis secreta (Homoptera: Diaspididae) from Korea. Transactions of Shikoku Entomological Society 15(3-4): 183-186.

\section{ACKNOWLEDGMENTS}

Thanks to the Director, Forest Research Institute and the Head, Entomology Division for providing research facilities; to Dr. J.S. Noyes of NHM, London and Prof. Mohd. Hayat, Zoology Department, Aligarh Muslim University, Aligarh for comments on the species and valuable suggestions.

\section{Key to the world species of Caenohomalopoda Tachikawa, based on females (Modified after Tachikawa et al., 1981)}

1. Fore wing with infuscate ray distad of venation perpendicular to anterior wing margin, and the adjacent whitish spot more or less rectangular; about $2.5 \mathrm{x}$ as long as wide; outer margin broadly rounded. Antenna with F4 slightly longer or as long as wide ................. shikokuensis (Tachikawa)

1A. Fore wing with infuscate ray distad of venation making an acute angle with the anterior wing margin, and the adjacent whitish spot wedge shaped; about $3-3.2 x$ as long as wide; outer margin narrowly rounded. Antenna with F4 slightly wider than long ............................................. 2

2. First funicle segment conical, basal width about half to third that of distal end, about as long as wide; remaining funicle segments a little wider than

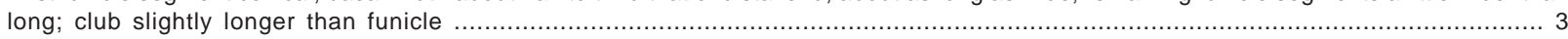

2A. First funicle segment sub-cylindrical, base about two-thirds that of distal end, at least a little longer than wide, rest of funicle segments

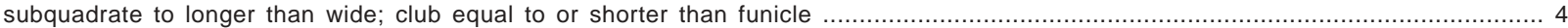

3. Ovipositor slightly protruded, about $0.1 \mathrm{x}$ as long as gaster; fore wing about $3.2 \mathrm{x}$ as long as wide; scape $3 \mathrm{x}$ as long as wide ... koreana Tachikawa

3A. Ovipositor protruded by $0.25-0.2$ of gaster length; fore wing about $3.0 x$ as long as wide; scape $2.8 x$ as long as wide ........ guamensis (Fullaway)

4. Antenna with scape 1.96x as long as wide; F1 2.6x as long as wide, F2 \& F3 1.4x and F4 1.2x as long as wide; club as long as preceding three and a-half funicle segments combined; ovipositor strongly exserted, about $0.5 x$ gaster length ........................................ Iongistylata sp. nov.

4A. Antenna with scape about $2.5 \mathrm{x}$ as long as wide; F1 shorter, rest of funicle segments subequal or quadrate; ovipositor not more than $0.33 \mathrm{x}$ gaster

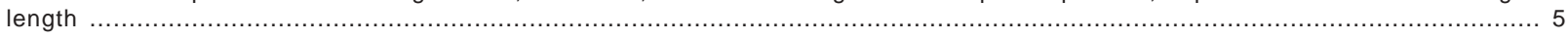

5. Antenna with scape about $2.6 \mathrm{x}$ as long as wide; F1 slightly less than $1.5 \mathrm{x}$ as long as wide, rest of the funicle segments subequal and almost quadrate; club as long as preceding three and a-half funicle segments combined; ovipositor exserted at the most by $0.33 x$ gaster length .......... nagaii (Tachikawa)

5A. Antenna with scape $2.5 x$ as wide as long; F1 as long as wide, rest of funcle segments wider than long. Ovipositor exserted by one-seventh of gaster length; fore wing $3 x$ as long as wide ................................................................................. longiclava Basha \& Hayat 